\title{
Kurse Sonografie des Bewegungsapparats und der Säuglingshüfte:
}

Alle diese Kurse finden im modernen Csiperkozsa-Konferenzia-Centrum in 6135 Csòlyospàlos (Ungarn) statt. Kurssprache Deutsch. Die Kurse werden verbunden mit einem lokalen Rahmenprogramm. Alle Einzelheiten zu den Kursen sind auf der Webseite der Sektion Bewegungsapparat: www.locomo.ch (Rubrik: Kurswesen) aufgeschaltet. Die Kurse entsprechen den Richtlinien der SGUM und werden testiert.

- Grundkurs Sonografie des Bewegungsapparats:

6. Sept.-9. Sept. 2012

Leitung: Dr. med. Beat Dubs
- Aufbaukurs Sonografie des Bewegungsapparats:

28. Juni-1. Juli 2012

Leitung: Dr. med. Beat Dubs

- Refresherkurs Sonografie des Bewegungsapparats:

1. Juni-3. Juni 2012

Leitung: Dr. med. Beat Dubs

- Refresherkurse Sonografie der Säuglingshüfte nach Graf:

4. Mai-6. Mai 2012

Leitung: Prof. R. Graf

- Refresherkurse Sonografie der Säuglingshüfte 15. Juni-17. Juni 2012

Leitung: Dr. Raoul Schmid

- Refresherkurse Sonografie der Säuglingshüfte 31. Aug.-2. Sept. 2012

Leitung: Dr. Markus Renggli 